I Universidade Jean Piaget de Cabo Verde, Unidade de Ciências

Humanas e Sociais, Praia, República de Cabo Verde

diracarvalho@gmail.com

https://orcid.org/oooo-000I-6756-I599

Carla Indira Carvalho Semedo'

\title{
"SOMOS DESCENDENTES!" - CONTRANARRATIVAS E AGENCIAMENTOS MUSICAIS DOS COLETIVOS DE TCHABETA NA ROÇA AGOSTINHO NETO (SÃO TOMÉ E PRÍNCIPE)
}

Não estavam de mãos dadas, mas as sombras deles estavam. Seth olhou para a sua esquerda e as sombras deles três deslizavam pela areia de mãos dadas. Talvez ele tivesse razão. Uma vida.

Toni Morrrison, Amada

Os arquivos do contrato administrativo para as roças de São Tomé e Príncipe ${ }^{\mathrm{I}}$ apontam para milhares de cabo-verdianos que, desde finais do século XIX até o último quartel do século $\mathrm{XX}$, se inscreveram na lista dos que foram aliciados à necessidade de contratar para as roças santomenses, com a homologação dos enunciados jurídico-oficiosos. Conforme decreto-lei de 8 de fevereiro de 1903 , o processo de recrutamento da mão de obra barata e escravizada nas então colônias - Moçambique, Angola e Cabo Verde -, visava: "salvaguardar as roças [em São Tomé e Príncipe] de monocultura de café e posteriormente de cacau, após a abolição da escravatura em I869" (São Tomé,I903).

Em paralelo com o recrudescimento, no espaço cabo-verdiano, do capitalismo colonial nas corporações/companhias agrárias e dos decretos-leis fabricando realidades marcadas pela "possibilidade de escolha", quotidianos de escravidão e de relações escravistas habitavam e irrompiam as relações sociais nas roças de São Tomé e Príncipe. Relações ancoradas a um processo de criação do enunciado de que a "única saída possível" a um quotidiano de fomes e a eminência de mortes era a evasão e o "alistamento" às roças santomenses. Os informes demográficos de Carreira (I984: I77) são muito esclarecedores quando assinalam que Cabo Verde, em I 947 com a população em cerca de I60 000 habitantes, tinha I 28000 (80\%) tidos como os "necessitados" do país.

Diante disso, o território Cabo Verde experimentava os efeitos do capitalismo moderno e a experiência das práticas escravistas - novamente o terror 
“SOMOS DESCENDENTES!” - CONTRANARRATIVAS E AGENCIAMENTOS MUSICAIS...

do tráfico negreiro irrompia na vida das pessoas cabo-verdianas em pleno século XX, décadas após o período abolicionista. Isso porque as narrativas dos cabo-verdianos que se alistaram e experimentaram o trabalho contratado nas roças santomenses de I940 a I970 e os descendentes dessa experiência atroz denunciam o fato de que, a despeito da abolição da escravatura no território português, a governamentalidade colonial portuguesa criou e instaurou nas roças santomenses de café e cacau um espaço onde vidas e trabalhos foram escravizados: mão de obra barata e escravizada de pessoas oriundas das então colônias, em pleno século XX. As precárias condições nos porões dos barcos/ navios que as transportavam ("gente vinha no porão como saco"), as configurações das então roças e das "senzalas", as normas rígidas e desumanas de funcionamento nas senzalas, o "castigo" do trabalho no mato, a violência e os maus-tratos que foram impingidos e a impossibilidade de dispor da própria existência por ser pessoa em situação de contrato povoam as narrativas e as experiências de meus interlocutores. ${ }^{2}$

Ainda, esse espaço laboral por se encontrar acoplado a uma gestão dos corpos e das formas de relações, marcada pelo intenso adestramento dos corpos de pessoas em situação de contrato, buscando garantir a produção econômica das roças sob fortes e duras regras e punições, reitera a constatação de que a realização do trabalho conforme esperado e definido pelos roceiros era a única garantia possível contra as duras e fortes punições corporais.

A despeito de Cabo Verde aparecer na memória social e nas práticas de pessoas cabo-verdianas atravessado e costurado pelas mobilidades a outros territórios, ${ }^{3}$ desde Europa, passando pelas Américas e África, a diáspora cabo-verdiana e a experiência do contrato no território São Tomé e Príncipe foi e continua sendo narrada na chave de "má migração". Por ser uma migração que reverbera, ainda, a experiência da escravidão e da africanidade intensamente repelidas, não cabe no tipo ideal de mobilidades, e São Tomé e Príncipe foi e continua sendo narrado como um território "impensável" e "improvável".

As várias e múltiplas narrativas elaboradas sobre o coletivo cabo-verdiano em São Tomé e Príncipe, quer os que experimentaram o acontecimento do trabalho contratado e da escravidão nas roças de café e cacau, quer os descendentes dessa experiência atroz, foram e continuam sendo, a todo instante, (re)inscritas numa chave de registro depreciativo. Essa migração, por incomodar e tensionar os debates acesos sobre a identidade cabo-verdiana, foi inscrita no regime de "um passado negr(eiro)o" que urge ser silenciado, criando, nesse processo de produção de verdades, vidas e narrativas que não importam, silenciando corpos e existências de sucesso. Entendo que, por ter sido e ainda ser rememorada nas práticas mnemônicas, nos regimes discursivos e nas historicidades como a "pior migração cabo-verdiana" (Nascimento, 2008, 2007; Semedo, 20I6), essas múltiplas narrativas e regimes de verdade ao (re)insistir em falar desse coletivo nessa chave, cria(ra)m uma "história 
única" (Adichie, 2009) deles. E, parafraseando Adichie (2009), o problema é menos que seja uma história irreal e mais que seja somente essa a única história a ser narrada sobre esse coletivo.

Recusando a "história única" narrada e a ela resistindo, nesse panorama de encontros e de discursividades, a despeito da experiência da migração para as roças santomenses - onde viveram relações e quotidianos de violência que os relegaram a uma condição de corpos e vidas escravizados, num estado ontológico continuum de dor -, essas pessoas cabo-verdianas denunciam, a todo instante, as narrativas e histórias desumanizantes e depreciativas elaboradas sobre elas, por meio de um trabalho de criação de outros modos existenciais. Nesse sentido, o argumento norteador do artigo é o de que as pessoas cabo-verdianas, em meio a uma experiência atroz do que foi o trabalho contratado nas roças de São Tomé e Príncipe, resistiram e criaram vidas e territórios existenciais nessas roças; vidas e projetos emancipatórios que existiram e persistem, recusando a "histórica única" que se elaborou da/com a experiência cabo-verdiana no arquipélago santomense.

Desses lugares de criações possíveis, o artigo propõe analisar o lugar das práticas do ritmo musicocoreográfico batuko, que se pode constituir em espaço político em que os cabo-verdianos em São Tomé criam contranarrativas que visam mostrar como a existência deles é reversa ao modo narrado quer em Cabo Verde, quer em São Tomé e Príncipe.

Antes de avançar, importa pontuar que entre os descendentes de pessoas cabo-verdianas, o batuko passa a ser denominado tchabeta; assim sendo, quando me referir à experiência em São Tomé e Príncipe, usarei a expressão êmica tchabeta.

Outrossim, decorrente da experiência de desterritorialização de pessoas cabo-verdianas em condição de contratados, de ser descendentes da experiência de trabalho contratado nas roças santomenses e, enquanto sujeitos percebidos nos territórios santomense e cabo-verdianos, como perdidos no mato, selvagens, o artigo recupera analiticamente as musicalidades enquanto artifícios acionados e acoplados dentro de um trabalho de criação de modos ontológicos de pensar o lugar dos "descendentes" cabo-verdianos em São Tomé, quer na relação com os forros santomenses, quer na relação com os cabo-verdianos não santomenses.

Com as narrativas de meus interlocutores e as narrativas musicais de tchabeta em São Tomé, viso mostrar que esse ritmo musicocoreográfico opera enquanto uma variação contínua dos modos existenciais cabo-verdianos. Assim, não interessa neste artigo conceber as práticas dos ritmos musicocoreográficos, no contexto diaspórico, numa chave de recriação de territórios e identidades enquanto uma réplica de um Cabo Verde imaginário, mas antes o modo como, a partir do ritmo tchabeta, as experiências, os encontros existenciais e as territorialidades aparecem marcadas por temporalidades e historicidades coexistentes, 
“SOMOS DESCENDENTES!” - CONTRANARRATIVAS E AGENCIAMENTOS MUSICAIS...

aglutinadoras, uma reatualização dos vários “cristais de tempo" (Deleuze, 20 I I). O que vai estar em jogo, portanto, é perceber como essa experiência diaspórica sinaliza outros modos existenciais, quer com o território prometido, quer com o território do desterro: de um batuko reprimido e silenciado do tempo colonial/ do branco em Cabo Verde para um tchabeta que permite outros espaços e outros modos existenciais no arquipélago de São Tomé e Príncipe.

\section{CORPOS, VIDAS E AFETOS DESTERRITORIALIZADOS}

Ritmo musical associado a mulheres e homens de grupos populares, o batuko é uma expressão musicocoreográfica caracterizada por canto antifonal acompanhado por fortes e ensurdecedoras percussões numa espécie de tambor - o tchabeta - que dão pulso ao ku torno. Ku torno é expressão êmica em crioulo cabo-verdiano 4 para o movimento de requebrar o baixo corporal feminino, em rebolar intenso e frenético dos quadris com rápidas flexões dos joelhos que magnetiza a atenção dos espectadores. A configuração espacial e corporal é caraterizada por mulheres/homens sentadas/os em círculo ou arco com o tronco levemente inclinado, pernas esticadas e cruzadas. A disposição na roda não é em função de estatuto social no grupo social ou escolha individual, mas do tipo de sonoridade que produz: bam-bam ou rapicada. Pelo fato de alternarem-se as sonoridades obtém-se seu equilíbrio - bam-bam, rapicada, bam-bam, rapicada, bam-bam ad infinitum - a fim de manter a harmonia entre as sonoridades do tchabeta e as da cantadeira (Semedo, 2009).

Se o período colonial criminalizou os modos de vida africanos, silenciou, exotizou e criminalizou o batuko (Nogueira, 20I5), nos modos de existência cabo-verdianos pós-independência, esse ritmo musicocoreográfico aparece sendo mobilizado na construção dos discursos identidários, acoplados ao discurso da constituição da nação cabo-verdiana no qual os legados da corporeidade negra, embora não tivessem sido silenciados, funcionam, segundo entendo, num movimento de folclorização e invisibilização desses corpos.

Outrossim, os modos de vida de pessoas cabo-verdianas bem como todo o debate sobre a identidade cabo-verdiana, buscando resolver o dilema decorrente dos encontros entre pessoas europeias e africanas, foram sempre construídos num jogo de forças entre um ideal de civilização europeia e um coletivo africano que experimentou a escravidão. O discurso da mestiçagem acionado e elegido visou estabilizar essas forças e manter novamente as fronteiras estáveis, supondo que a figura elaborada do mestiço cabo-verdiano as condensaria e hierarquizaria (Dos Anjos, 2006, Fernandes, 2002). A despeito do fato de, durante o período colonial, a africanidade ter sido silenciada num discurso de mestiçagem acoplada à ideia criada e instrumentalizada pela Administração Colonial de que os cabo-verdianos seriam segundos europeus ou "europeus de segunda", os modos de vida escravistas novamente devastariam a vida da pessoa cabo-verdiana (Semedo, 20I6). 
Nhu Bana, Nhu Frank e Nhu Mamede, trazidos na condição de contratados, reiteravam o uso da categoria segundos europeus, a ideia de que os cabo-verdianos, em decorrência da mestiçagem, estariam mais próximos aos modos ditos europeizados, embranquecidos e civilizatórios. E, por conta disso, em diferenciação corporal e cultural em relação aos outros africanos vindos do continente (angolanos e moçambicanos) como também aos nativos santomenses. Ao rememorar a experiência da migração contratada, Nhu Bana mostra-se afetado pela não reatualização de uma virtualidade aparentemente já dada - a de que o indigenato não se aplicava mais em Cabo Verde, diferentemente das outras então colônias da administração portuguesa, e, por conseguinte, o cabo-verdiano continuaria sendo visto como “cidadão", situação então vigente em Cabo Verde: "Quando gente chegou, gente pensou 'branco' daria boa cama para dormir, boa comida... Credo ehh...! Deu gente fubá de milho podre e peixe salgado podre de comida e deitar no chão só...".

Por ter sido percebida num regime discursivo, a "migração para o Sul"5 desnuda, por um lado, questões das relações identitárias constituintes da pessoa cabo-verdiana, entre as quais o jogo de forças entre o imaginário da África e o da Europa. Numa base em que o continente africano era "diluído" e renegado a ponto de a identidade racial ser continuum à concessão de nação e do Estado, "ser cabo-verdiano e não ser africano", ao mesmo tempo em que se projetavam possibilidades de uma aproximação Cabo Verde-Europa (Dos Anjos, 2006; Fernandes, 2002; Furtado, I987).

Por outro lado, o processo de concebê-la e de narrá-la na chave de um suposto "atraso cultural" silencia um movimento de denúncia que sinaliza os usos desses fatalismos na criação e na propiciação de um deslocamento de corpos braçais inseridos num sistema jurídico de trabalho contratado escravo. Igualmente, o legado escravista e os modos existenciais de pessoas africanas materializados nas práticas musicais, no caso o batuko, são lidos na mesma chave de silenciamento. Como frisado, ainda que no pós-independência essas práticas tivessem deixado de ser criminalizadas e reprimidas, e passassem a fazer parte da cena musicocoreográfica no território cabo-verdiano e na diáspora, percebo uma tentativa de folclorização dos corpos e das habilidades performáticas, incentivando os deslumbres, os gritos e zombarias na plateia. Assim, os regimes de verdades que elegeram o "deleite dolente da morna", por recusar e silenciar formas outras de experiências sonoras e performáticas, realocam os legados africanizados numa escala hierárquica de não sublevação civilizante.

"Descendente" do evento contrato, a quinquagenária Zizi, nascida em São Tomé, viveu sua infância na ilha do Príncipe, tendo crescido com o batuko. Passados dez anos, retorna para São Tomé, integrando-se no Coletivo de Batuko Ouro Verde, na roça Agostinho Neto. No início da formação desse coletivo, antes de a integrante Ricarda ter partilhado os ensinamentos das artes de fazer 
“SOMOS DESCENDENTES!” - CONTRANARRATIVAS E AGENCIAMENTOS MUSICAIS...

descobertas em Cabo Verde, o instrumento percussivo era de material plástico. Dos "plásticos enrolados e/ou plásticos com roupa velha no interior", Ricarda sugeriu um novo feitio: uma lata de $250 \mathrm{ml}$ a suster tecidos ou roupas velhas, como se de um funil se tratasse: a base alongada e a superfície plana e dura na qual se bate, criando uma caixa de ressonância percussiva, envolvida por couro sintético, ficando a parte afunilada entre as coxas para garantir firmeza explica Zizi. Esse formato manteve-se igual também no outro coletivo da roça Agostinho Neto, o Raiz di Terra e, em vários momentos, ambos os coletivos faziam questão de enfatizar o fato de o instrumento estar em consonância com o usado pelos grupos de batuko e funaná em Cabo Verde e, na diáspora cabo-verdiana na Europa, particularmente em Portugal. Nos coletivos de tchabeta de outras roças, era visível ainda, o uso de bolsas de plásticos enrolados com roupa gasta por dentro.

A presença e a monumentalização das práticas ditas culturais de um povo são lidas em muitas das pesquisas sobre as diásporas cabo-verdianas (particularmente nas pesquisas sobre práticas culturais e modos de ser e estar do cabo-verdiano) enfatizando a ideia de que "onde existem os cabo-verdianos, há um território Cabo Verde" intato, criado e produzido, à procura de sempre manter essa ligação com o território original e criando réplicas (Cidra, 2008; Barbosa \& Ramos, 2008; Góis \& Marques, 2008; Ribeiro, 2012). Distanciando-me dessa perspectiva de recriação da tradição e da ideia de uma cabo-verdianidade, que perpassaria e habitaria a pessoa cabo-verdiana, argumento que os cabo-verdianos nas roças santomenses sinalizam outras dimensões, pois, como pontua Gilroy (200I), há toda uma "articulação" entre dinâmicas locais e globais, e a diáspora negra, o Atlântico Negro, em nenhum momento, se resume a uma unidade homogênea, pois as conexões e as relações tecidas e elaboradas no plano local são potencialmente múltiplas e singulares.

Por conseguinte, importa perceber de que forma a experiência desterritorializante do trabalho contratado eclodiu na vida de pessoas cabo-verdianas e em suas práticas musicocoreográficas, bem como o tchabeta passa a operar enquanto um espaço de criações existenciais nas roças santomenses. Assim, partindo do pressuposto de que os ritmos musicocoreográficos materializam noções de criação de corpos e pessoas, apresento ao longo do artigo criações de contranarrativas e contra-histórias no coletivo cabo-verdiano em São Tomé.

\section{TCHABETA CABO-VERDIANO EM SÃO TOMÉ}

Comumente, o regime de verdade veiculado e reconstruído de que os modos cabo-verdianos estão esvaziados das possíveis práticas e existências africanas e marcados por uma dita europeização é mobilizado quando se narra e se fala dos corpos e das pessoas descendentes do trabalho escravizado e do que foi a experiência do trabalho contratado nas roças santomenses. A vida no mato, a coleta dos alimentos naturais, a conformação das casas ainda no modelo sen- 
zalas são inscritas nas narrativas e nas tentativas de desumanização que os veem "como perdidos no mato" por "viverem ainda no meio do mato", "viverem em senzalas, a comer dos frutos do mato".

Francisca, sexagenária beneficiária da pensão do Estado cabo-verdiano, sai todas as madrugadas na companhia do filho para ir buscar, mato adentro, os búzios de mato e, revendê-los na cidade. Assim como Francisca, um pouco por todas as roças, muitos saem na madrugada para coletar os búzios de mato, com candeeiro a petróleo e facão na mão: "não tem mulher, não tem homem, vai só. Não tem que estar parado não, não dá, tem que buscar meio de vida”. Bastante usual na ilha de São Tomé, os búzios de mato são grandes caracóis usados no preparo de vários pratos gastronômicos, molhos apimentados à base de leite de coco, azeite de palma (azeite de dendê), ou fritos/grelhados, substituindo outras proteínas animais, pois, mesmo na cidade, as carnes bovina e suína costumam ser as mais caras no mercado, estando seu consumo, por vezes, limitado aos coletivos com maior poder aquisitivo. Os búzios de mato, coletados no mato sem custo para os moradores das roças, constituem forma de geração de renda de muitas famílias nas roças e na cidade, além de garantir o consumo de proteína animal.

Apesar das precariedades existentes nas roças, em umas mais acentuadas do que em outras, agudizadas pelos problemas estruturais do país, particularmente a eminente instabilidade política e a pobreza estrutural, a ideia de que na roça se passa fome é inconcebível entre meus interlocutores. E o perigo das narrativas únicas, elaboradas com as paisagens arruinadas das então "casas de patrão", "casas de empregados" e "senzalas" (Semedo, 20I6), nas suas formas de ser e de estar, é criar uma "história única" acoplada ao registo de fome e de miséria. Completamente dissociado e irreal, porém, o regime de fome sufoca-se e implode.

Igualmente, o enunciado de que a migração para as roças santomenses não foi o "tipo-ideal" da migração cabo-verdiana constrange e impossibilita olhar o mundo como percebem-no e como procede-se. "Viver em senzalas, a comer dos frutos do mato", faz do mato um território povoado de afetos e relações, e "a floresta e os trabalhos nas parcelas concedidas pelo governo santomense" traduzem a materialização de um projeto emancipatório, o de poder fazer a casa própria sem a compra do terreno e usar a madeira do mato, a baixo preço, para a construir.

Nessa chave, o território santomense foi se constituindo, entre os coletivos cabo-verdianos, num espaço em que houve a experimentação da reterritorialização não só num estado ontológico de dor, na vida escravizada com o contrato nas roças, como também, no encontro com um território verdejante, sem o espectro da fome. Em certa medida, o projeto de um espaço verde, com chuva e não mais faminto, como Cabo Verde na época, reterritorializou-se em São Tomé e Príncipe, onde uma espécie de um novo território existencial cabo-verdiano foi elaborado, bem como as experiências musicocoregráficas cabo-verdianas.

Se até os anos I990 o batuko se restringia ao espaço presencial, a partir do século XXI (2000) passa a circular pelos espaços físicos enquanto realidade audio- 
“SOMOS DESCENDENTES!” - CONTRANARRATIVAS E AGENCIAMENTOS MUSICAIS...

visual. Era desnecessário um deslocamento físico e social, dado que a cena musicocoreográfica audiovisual permitia aos sujeitos formas de acessibilidade e visibilidade do batuko. Ao mesmo tempo, permitia aos cabo-verdianos na diáspora, no caso em São Tomé e Príncipe, acesso às criações feitas em Cabo Verde e pelos cabo-verdianos na diáspora. Conforme narra Flora, integrante do Coletivo de Tchabeta Ouro Verde, as tecnologias foram se constituindo num artifício de ensinamento e de aprendizagem das artes percussivas quer para ela, quer para as outras integrantes, observando as artes de fazer dos grupos em Cabo Verde e/ou na diáspora.

A roça Agostinho Neto, de 2007 a 20ıo, foi identificada unicamente pelo Coletivo de Tchabeta Ouro Verde, que atualmente tem I I integrantes cuja idade varia de dez a 70 anos: Sônia (atual chefe do coletivo), Zizi (a voz lírica do grupo), Nha Ninha (a única anciã do coletivo), Lena, Tina, Bia, Flora, Aneurite, Didy, Maite e Denise, as três últimas são as dançarinas do ku torno - acompanhadas por Zizi. Em 20ıo, em decorrência de vários ciclos de tensões internas, o grupo se fragmenta, e emerge o Coletivo de Tchabeta Raiz di Terra, atualmente com cerca de 12 integrantes: Ingrácia, Nina, Lúcia, Jo (irmão da Ingrácia e homem de Marcelina, faz tchabeta e dá ku torno), Ana, Ticiana, Marcelina (a voz lírica do grupo, substituída nas necessidades por Ingrácia e Lúcia), Mena, Ita (a única não descendente de Cabo Verde), Ruth, Ju e Tatiana.

Como mencionado, ainda que aparentemente as dinâmicas pós-coloniais e a globalização tenham também potencializado as artes de fazer batuko na diáspora cabo-verdiana no arquipélago santomense, as vicissitudes do evento desterritorializante da migração contratada introduziram variações na experiência musical, como é frisado pelas integrantes dos coletivos Ouro Verde e Raiz di Tera.

Um exemplo disso é o fato de que, enquanto em Cabo Verde e nas diásporas em que se brinca o batuko, quando se usa a categoria batuko é sempre em alusão ao ritmo musicocoreográfico e a categoria tchabeta ao instrumento de percussão e à prática percussiva, na diáspora cabo-verdiana em São Tomé ter-se-ão deslocado as categorias êmicas. O ritmo musicocoreográfico batuko entre os descendentes de cabo-verdianos em São Tomé virou tchabeta, e o instrumento de percussão e a prática percussiva tchabeta virou batuko. Igualmente, as categorias percussivas alusivas às sonoridades, em vez de ser "bam-bam", virou "pam-pam", permanecendo quase parecidas, mas sendo modificada quando outros movimentos corporais emergem. No grupo somente Zizi faz a variação da "rapicada", que chamam de tchabeta: o braço levanta, e a mão faz o movimento com os braços sob o instrumento virado para o corpo e intensifica o som, dobrando o tronco; e, quando a mão cansa, levanta os dois braços, como se estivesse pausando e se preparando para retomar o movimento percussivo. Zizi reparou nessa técnica corporal e percussiva quando do encontro com outras coreografias feitas em Cabo Verde e quis aprender, por entender que torna a 
"percussão mais forte e o batuko mais intenso".

Por ser Nha Ninha a única anciã no grupo, questionei-a, ciente de que as variações nas práticas e nas nomenclaturas poderiam ser uma chave relevante nas artes de fazer tchabeta. "Minha filha, tempo antigo assim chamavam, nós seguimos com a tradição." Visto que essas artes de fazer seriam remanescentes à primeira onda da migração de cabo-verdianos para São Tomé e tendo em conta que mesmo entre os registros dos outrora fazedores de batuko, entre os quais Nha Nacia Gomi e Untoni Denti D'Oru, ou pesquisadores folcloristas, como Tomé Varela da Silva (1985, I988) e António Gonçalves (2006), não há referência, possivelmente seriam as primeiras manifestações da criação do território Cabo Verde e das socialidades dessa diáspora no arquipélago santomense.

Igualmente, as narrativas musicais de ambos os coletivos de tchabeta operam na rememoração das experiências silenciadas enquanto um ato político e na criação de um espaço em que as musicalidades, o tchabeta, a africanidade e os modos de vida nas roças constituem a atualização menos de uma mobilidade malsucedida e mais de modos de vida cabo-verdianos, de criação de um território cabo-verdiano negro e africano no território santomense. Das experiências quotidianas vividas, rememoradas e partilhadas, trago duas narrativas musicais do coletivo Ouro Verde:

3 de fevereiro - música de escravos

Era um dia 3 de fevereiro, tempo de massacre

Santomenses passaram muito mal aqui no solo de ponte de Obrigada É no solo de São Tomé, humhum jovens quanta tristeza em contar. Quando chegou 25 de abril [I975], santomenses tomaram liberdade. Africanos preparam para celebrar, oh, jovens, quanta tristeza em contar. Dizemos santomenses são de resistências, cabo-verdianos de resistências, moçambicanos de resistência, angolanos de resistência.

Música: Era na 46, 47

Era na 46, 47, minha mãe e meu pai vieram para São Tomé procurar trabalho

Porque Cabo Verde não tinha trabalho

Minha gente agora como Cabo Verde está bom de viver

Aqueles que conseguiram ir foram e nunca mais voltaram, aqueles que não conseguiram ir ficaram todos por cá

Nós somos descendentes, filhos de cabo-verdianos que nasceram em 
São Tomé e Príncipe, vamos manter nossa cultura firme.

Ambas as narrativas musicais aludem, ainda que em registros temporais e espaciais diferenciados, aos usos e aos efeitos do sistema colonial na conformação de socialidades e na criação de projetos de vida. 3 de fevereiro ou o massacre de Batepá, ocorrido a dois e três de fevereiro de I953, um marco na historiografia santomense celebrada e rememorada nos rituais governamentais, faz alusão a uma série de chacinas perpetradas pelo então governador português Carlos Gorgulho. As tentativas de subjugação da sociedade santomense, aos desmandos do então governador, visavam à manutenção da estrutura colonial de roças e à incorporação dos forros, esses ainda reticentes em se tornar serviçais nas roças ou pessoas escravizadas.

Cabe frisar que os abusos e as violências perpetrados aos trabalhadores serviçais - muitos, no desespero, fugiam para o mato, sendo referidos como os 'fugidos' - pelos capatazes e feitores ainda faziam parte do quotidiano laboral dos cabo-verdianos [angolanos e moçambicanos] contratados para as roças santomenses nos finais dos anos I940 (Semedo, 20I6). O massacre de Batepá vem intensificar a insurgência contra o colonialismo português e o trabalho escravizado nas roças, provocando mudanças nas relações sociais nas roças, até então tidas como escravistas, e a fuga do governador português Carlos Gorgulho. De centenas e milhares de santomenses e cabo-verdianos [angolanos e moçambicanos] em situação de contrato, muitos teriam sido torturados até a morte por relutarem em se curvar ao regime laboral vigente nas roças. Com a narrativa musical 3 de fevereiro:

É história que nós ouvimos de quem passou o massacre, tiveram vida massacrada, conversámos com eles para vermos como as coisas na época correu e para vermos como colocar na letra. Antigamente tempo de massacre e muitos caboverdianos, angolanos, moçambicanos, santomenses todos passaram muito massacre, morreram mal, com porrada, acorrentados, ficaram muito mal. Tem os que sobreviveram, tem aqueles que morreram, e aqueles que morreram morreram numa situação difícil, penosa, com injúrias, maltratados, falta de água e de comida. Mas aqueles que sobreviveram lutaram mesmo, outros mataram branco, para conseguirem sobreviver e conseguiram sobreviver. Fizemos essa música porque muitos passaram mal, acorrentados, alguns fugiram para o mato, não ouviste falar de fugidos!? Passaram mal com fome, com chicote nas costas (Zizi).

Na narrativa musical 'Era na 46, 47' rememora-se o acontecimento da migração contratada, do qual os integrantes do tchabeta são "descendentes", e as narrativas do quotidiano de fomes e de mortes em Cabo Verde, as quais serviram de mote ao sistema de contrato laboral escravista.

Aqueles contratados que vieram de Cabo Verde, conforme nos contaram, Cabo Verde estava mal, difícil, vieram contratado. Muitas pessoas tinham vontade de vir cá em busca de vida melhor. Eu sou filha daqueles que vieram, descendente dos que vieram, de filhos de cabo-verdianos. Estamos em São Tomé agora, nós não somos cabo-verdianos, somos descendentes de cabo-verdianos, mas nasce- 
mos em São Tomé. Nós seguramos a cultura da nossa mãe e do nosso pai para não cair, porque eles vieram, vieram com tradição deles, nós também vamos segurar a tradição para não deixar cair. Maioria de nós que estamos cá, somos só descendentes, porque dos que vieram ficaram poucos, muitos já morreram, nós somos filhos cabo-verdianos que está em São Tomé e Príncipe. Nós, os descendentes, tem que pegar tradição com toda força para não deixar cair (Zizi).

Ambas as narrativas musicais fazem dos atos de rememorar atos de subjetivação de produção de novos sujeitos em afeção, por formas novas e múltiplas de vivenciar as unidades de medida do tempo. Escapando à historiografia oficial construída sobre o acontecimento da migração cabo-verdiana contratada e da escravidão em São Tomé e Príncipe, em pleno século XX, as narrativas musicais sinalizam como os coletivos "descendentes" na roça Agos tinho Neto concebem-se e, simultaneamente, criam condições de possibilidade aos sujeitos, quer na produção da noção de self, quer enquanto mecanismos de rearranjos das experiências passadas vividas e/ou partilhadas.

As narrativas musicais falam sobre algumas questões das agendas político-governamentais, outras aludem à violência, gravidez na adolescência, toxicodependência (bebidas alcoólicas e estupefacientes) nos jovens, a relações familiares e poligamia, maus-tratos e abusos infantis, tal como o fenômeno de "menino de rua", questões que povoam o quotidiano dos integrantes do coletivo. Também as narrativas rememoram a experiência do trabalho contratado e da migração cabo-verdiana para São Tomé e Príncipe, como também os fluxos migratórios de familiares e/ou integrantes dos coletivos para Portugal, Cabo Verde e Angola. Por conseguinte, quer com as narrativas musicais sobre a condição de vida, quer com a reatualização de experiências passadas, está a todo instante em jogo, um movimento do coletivo cabo-verdiano em São Tomé, por meio desse agenciamento musical, de romper com a história única construída e criar outras histórias:

eu acho que a imagem que levam de São Tomé é também um pouco pejorativa, de modo a denegrir também um pouco a vivência, a imagem das comunidades. De fato, os cabo-verdianos passam aí dificuldade, então eu acho eles veem somente afirmar aquilo que é mau, que os cabo-verdianos estão a viver. Mas há também cabo-verdianos que estão a viver muito bem, há filhos cabo-verdianos que já foram ministros, ocuparam altos cargos no governo. Mas, isso não levam. Vêm só buscar esta situação das comunidades mais desfavorecidas. [...] Nós devemos também mostrar as boas coisas, ou fazer junção das duas coisas, porque há cabo-verdiano no bairro de Hospital vivem muito bem. Têm suas próprias casas, têm seus negócios. Há cabo-verdiano noutra zona que tem sua roça, tem seus animais. Então eles vêm mais buscar estas pessoas que, por infelicidade, não deram muito bem na vida, vivem uma situação mesmo lamentável. Eu acho que devia mudar também um pouco o cenário (Saydel, descendente de Cabo Verde, nascido em São Tomé) 
“SOMOS DESCENDENTES!" - CONTRANARRATIVAS E AGENCIAMENTOS MUSICAIS...

\section{“CRISTAIS DE TEMPO"... MUSICALIDADES E AS TEMPORALIDADES}

Batuko foi construído em Cabo Verde pelos negros escravizados, durante o processo de colonização, e, diferente das outras ilhas, se enraizou na ilha de Santiago; segundo os estudos históricos, em Cabo Verde, a escravidão regulamentada esteve vigente até meados do século XIX. Contudo, as literaturas histórica e folclorista (Gonçalves, 2006; Nogueira, 2015) afirmavam que convivência da prática do batuko com os brancos europeus e, particularmente, com a Igreja enquanto instituição reguladora das práticas dos sujeitos era marcada por repressão e proibição.

Com o movimento de descolonização em Cabo Verde, processos variados de modernização têm lugar no campo da cultura, entre os quais novas dinâmicas na produção das formas tradicionais duramente reprimidas no período colonial, como é o caso do batuko. Na dinâmica das relações pós-coloniais, os shows de batuko como signo de identidade nacional, a produção musical de vários grupos de batuko em CD/DVD, assim como apropriações do gênero por outros grupos sociais (classe média alta) sob outros moldes, marcadores de diferença dos grupos populares, ganham visibilidade em Cabo Verde. Igualmente, na diáspora cabo-verdiana esse movimento começa a ter efeitos, particularmente a partir de $200 \mathrm{I}$.

Conquanto os modos e artes de compor e experimentar as musicalidades em outras diásporas cabo-verdianas visam à recriação de um território Cabo Verde (Cidra, 2008; Barbosa \& Ramos, 2008; Góis \& Marques, 2008; Ribeiro, 20I 2), a diáspora cabo-verdiana no arquipélago santomense é povoada por outros movimentos existenciais, como ilustra a experiência do ritmo musicocoreográfico tchabeta. Argumento que o acontecimento do trabalho contratado e escravizado nas roças santomenses opera enquanto um marcador de diferenças, quando se percebe como e de que forma o movimento de desterritorialização de corpos e pessoas cabo-verdianas atravessados por tentativas de invibilização e desumanização possibilit(ou)a atualizações e criações dos múltiplos territórios Cabo Verde, em São Tomé.

As variações em que o ritmo tchabeta foi inscrito, transformando expressões êmicas, falam do movimento de uma diáspora cuja chamada terra prometida se tornou uma espécie de país do desterro. E, em São Tomé, a terra do desterro ter-se-á tornado a terra prometida, a realização de um projeto emancipatório, onde a natureza e a chuva provedora dos alimentos impossibilitarão o espectro da fome, criando-se modos de existência da pessoa cabo-verdiana. As musicalidades e as práticas do tchabeta constituirão, assim, artifícios acionados na criação de um território e corporeidades resultantes de encontros produzidos e propiciados pelo acontecimento desterritorializante da migração contratada para as roças santomenses.

Outrossim, as socialidades e multiplicidades dessa diáspora cabo-verdia- 
na, enquanto criação de outros modos existenciais na roça, outros territórios Cabo Verde, mostram que está em jogo sinalizar como as relações com as espacialidades, o mato, a coexistência com a natureza em toda a sua plenitude, são recuperadas pelos descendentes de pessoas cabo-verdianas na roça de Agostinho Neto, e não só como uma contranarrativa reatualizada nas narrativas musicais do ritmo tchabeta. As narrativas, as contranarrativas, enfatizam o cuidado de como narrar e como conceber as corporeidades, e são acionadas para demarcar a forma como os cabo-verdianos nas roças são vistos - "perdidos no mato, animalizados" - pelos santomenses e pelos cabo-verdianos não santomenses. 0 modo como essa diáspora se pensa na relação com Cabo Verde opera numa relação dialética para se pensar esses lugares e essas ontologias, em que as musicalidades condensam os vários afetos, forças e sociabilidades, subtraindo, anulando ou intensificando-os nesses encontros.

Destarte, a experiência do tchabeta constitui artifício acionado e acoplado dentro de um trabalho de criação de modos ontológicos de pensar o lugar dos descendentes de cabo-verdianos em São Tomé, quer na relação com os forros santomenses, quer na relação com os cabo-verdianos não santomenses, destacando que não estão "perdidos no mato", como tem sido postulado, bem como que Cabo Verde não é "sempre" um lugar melhor que São Tomé e Príncipe.

Outrossim, percebendo os agenciamentos musicais enquanto atualização de um passado vivido que vai sendo atravessado e atualizado num presente vivido, a experiência temporal de pessoas cabo-verdianas nas roças santomenses permite revisitar as unidades de medida do tempo e as temporalidades. Desta feita, permite um diálogo com a perspetiva deleuziana sobre tempo e memória, quando os atos de criação musicais e as narrativas musicais de tchabeta possibilitam criar movimentos trans-históricos não porque restituem outras relações às condições de descendentes de pessoas cabo-verdianas e do trabalho contratado na sociedade santomense, mas um movimento a despeito delas, pois "a história só pode recuperar ou recolocar nos sistemas pontuais" (Deleuze \& Guattari, 2008: 95), uma vez que agenciam realidades e mundos outros.

Do mesmo modo, pelo fato de o tchabeta ter sido e estar sendo criado em decorrência desses vários momentos de desterritorialização e reterritorialização de pessoas cabo-verdianas nas roças santomenses, percebo um certo paralelismo em pensar a prática musicocoreográfica enquanto um "cristal de tempo"' (Deleuze, 20II), no qual várias temporalidades se aglutinam e não se anulam, pois possibilita atravessar as várias temporalidades, não mais o "tempo de castigo", do contrato, pois, "um presente do futuro", não mais haverá o "branco" a subjugá-los; nem aos mais jovens cabe rememorar o contrato, visto que a apropriação da roças e as possibilidades de poder construir uma moradia, sem necessitar da autorização prévia da Edilidade 
“SOMOS DESCENDENTES!” - CONTRANARRATIVAS E AGENCIAMENTOS MUSICAIS...

local, atualizam um projeto emancipatório de um presente-passado.

Embora, o batuko em Cabo Verde tenha alcançado projeção transnacional, entendo que tal como o ritmo musical santiaguense funaná (ainda presente entre as pessoas cabo-verdianas nas roças), o ritmo tchabeta em São Tomé e Príncipe teria sido apropriado enquanto um espaço de criações, resultante da migração forçada e escravizada nesse arquipélago. Nessa chave, no tchabeta percebo um campo de possibilidades de atravessamento do tempo e narrativas não só por ser uma expressão êmica reversa, mas por ser agenciada para criar outras versões da história, tal como outros sujeitos na/da história. Com o tchabeta, a territorialidade Cabo Verde aparece enquanto "um presente do passado", um passado de fomes deixado nesse arquipélago, e que constitui ainda um presente pelas e nas marcas corporais da fome, das então pessoas em situação de contrato, à "necessidade de se sucumbir a ter que vir no navio pra São Tomé", resignadas à sorte do destino - "sobrevivemos à fome... a vida pode melhorar" - e, em seguida, se reterritorializar num "presente melhor" em São Tomé e Príncipe, apesar dos reveses do sul, quando asseveram: “São Tomé e Príncipe é bom e se vive 'remediado', como também é o 'inferno'; igualmente Cabo Verde parece ser um 'país bom', mas 'não de viver, só pra passear'”.

O ritmo tchabeta, reitero, constitui paralelismo a um cristal de tempo, que aglutina temporalidades atualizadas por pessoas marcadas e povoadas por historicidades múltiplas, pois não somente os integrantes dos coletivos do tchabeta vivenciaram temporalidades e historicidades múltipas, como também os ouvintes desse ritmo são povoados por essas multiplicidades e singularidades históricas, compondo assim múltiplos e singulares Cabos Verdes. Um "presente do passado" de 'Cabo Verde' dos anos I 940 ressoando na memória dos idosos, marcados e maculados pelas secas, pela fome, pelos usos coloniais e capitalistas acoplados a um quotidiano de fome e à eminência de mortes, que se desmancha num "presente do presente" do encontro de um "Cabo Verde" em que pulsa a modernização, nos marcadores e nas materialidades que acionam: as estradas, a iluminação e as infraestruturas. Um "Cabo Verde" em que a memória da fome e de navios atracados nos portos, aguardando pessoas em situação de contrato para as roças santomenses, não cabe mais nesse quotidiano, é uma "memória passada não mais rememorada".

O encontro de "um Cabo Verde" retoma também as outras "pontas de presente" (Deleuze, 20I I), ainda que sob modulações diferenciadas quer nos cabo-verdianos em condição de contratados, quer nos "descendentes". Diferentemente do que ocorreu aos cabo-verdianos que vieram em situação de contrato para as roças, os modos narrativos e de agência dos "descendentes" passam por conceber Cabo Verde como um "presente do futuro" onde outras experiências e outros projetos de vida podem ou poderão ser criados - seja dentro de um projeto migracional menos de retorno ao país dos pais e mais como um destino migracional, seja em outra chave como um destino de passagem, dentro da existência nômade e não de permanência, já que São Tomé e Príncipe permanece um país bom para 
se viver.

Importa sinalizar, no coletivo dos descendentes, "Cabo Verde" constitui-se menos enquanto um "presente do passado", em que nem compartilham nem acionam as narrativas das fomes, das secas para produzir os arranjos dos modos de existência - caso dos seus pais e avós cabo-verdianos - e menos também como um terra prometida, da qual almejam conservar os legados culturais: a diáspora que procura a manutenção e a recriação dos traços tidos como idiossincráticos do povo cabo-verdiano. E, mais, se se pensar como a possibilidade de existir em São Tomé e Príncipe, criando-se nessa retroalimentação com a sociedade santomense, na fala de Gualter: "Cabo Verde está lá, nós estamos aqui. Nós somos descendentes de cabo-verdianos que de lá vieram, que são os cabo-verdianos". Assim, a prática do tchabeta constitui um campo de possibilidades tanto aos que vieram em situação de contrato retomar esse Cabo Verde de fomes, para que a história dessa migração seja rememorada por suas falas, como também, para os descendentes, possibilidade de falar da condição de ser descendente dessa experiência atroz e, apesar disso, ter conseguido criar vidas numa experiência de dor e sofrimento.

As narrativas e práticas de meus interlocutores - por afirmar a potência do tempo e como o passado, mais que um rememorar, torna-se numa possibilidade de transformação, subjetividades sendo afetadas e potencializadas no encontro com as múltiplas temporalidades - nos mostram que o tchabeta não é uma tentativa floclorista de replicar um Cabo Verde no espaço santomense, mas é principalmente poder criar um território existencial naquela que inicialmente era a terra do desterro: São Tomé e Príncipe. Quando agenciam outras possibilidades e realidades com o tchabeta, criando outros sujeitos num processo histórico que visou desumanizá-los, criam outras histórias e rompem com a história única que deles foi criada e com (n)a qual são narrados, nos lembram as leituras deleuzianas sobre Henri Bergson (Deleuze, 20 I : I03), de que "o tempo não é o interior em nós, é justamente o contrário, a interioridade na qual estamos, nos movemos e mudamos".

Recebido em 26/6/20I9 | Revisto em I9/5/2020 | Aprovado em 20/5/2020

Carla Indira Carvalho Semedo é doutora em antropologia social pela Universidade Federal do Rio de Janeiro/Museu Nacional, mestre em antropologia social pela Universidade Federal do Rio Grande do Sul e graduada em sociologia pela Universidade Jean Piaget de Cabo Verde, onde atua como professora auxiliar. Tem como áreas de interesse: práticas de cura, musicalidades, diáspora caboverdiana em São Tomé e Príncipe, e memórias coloniais. Publicou "Musicalidades das cabo-verdianas nas roças de São Tomé e Príncipe" e "Noções estéticas na performance do batuko: experiência etnográfica entre as batukadeiras de São Martinho Grande (Ilha de Santiago-Cabo Verde)". 


\section{NOTAS}

I Este artigo propõe uma releitura dos resultados da pesquisa realizada no âmbito do doutorado em antropologia social pelo Programa de Pós-Graduação em Antropologia Social da Universidade Federal do Rio de Janeiro/Museu Nacional, com apoio de bolsa Capes PEC-PG. A tese resultante de tal pesquisa debruça-se sobre a comunidade cabo-verdiana residente nas roças de São Tomé e Príncipe, explorando tanto as narrativas dessa migração como as experiências dessa comunidade no presente tempo etnográfico.

2 Sobre a metodologia, a pesquisa de campo foi realizada exclusivamente na ilha de São Tomé de janeiro a julho de 2013 e de novembro de 2014 a janeiro de 20I5. Interessou registrar as narrativas dos idosos cabo-verdianos alusivas à experiência de contrato e, no Arquivo Histórico Nacional de São Tomé e de Cabo Verde, pesquisas sobre a migração contratada. Num segundo momento, fez-se etnografia do quotidiano e as relações na roça Agostinho Neto a partir do contato com os dois grupos de Tchabeta lá existentes.

3 Conforme os registros históricos (Carreira, I977; Carreira, I983; Andrade, I996), a formação da diáspora cabo-verdiana teria começado entre finais do século XIX e inícios do XX, muito condicionada pelas vulnerabilidades ecológica e ambiental (clima árido e escassez de chuvas). Inicialmente para os Estados Unidos da América nas então embarcações pesqueiras (de baleia), para São Tomé e Príncipe e Angola, posteriormente Europa, outros países da Africa e América.

4 O crioulo cabo-verdiano é a língua de conversação - a língua materna. O português cabo-verdiano, a língua oficial, aparece falado unicamente em situações cerimoniais, nas salas de aula, nos manuais escolares e na mídia.

5 Conforme registros históricos (Carreira, I984), a migração cabo-verdiana para São Tomé e Príncipe - "santa praça" - se equipara a uma "condenação a degredo" e, em decorrência, recriada numa chave de "migração pra Sul". Segundo pontua Carreira (I984: I75), "a ida dos cabo-verdianos para as roças de São Tomé e Príncipe foi sempre considerada no arquipélago uma deportação ou mais propriamente uma condenação a degredo - sem se ter co- 
metido crime algum. Tanto é assim que não se dizia que alguém embarcou para S.Tomé, mas que 'embarcou para o Sul', alusão ao envio de condenados de delitos comuns pelos Tribunais ordinários para Angola, onde iam cumprir penas - como era corrente. Por outro lado, no consenso geral o 'dar nome' ao agente recrutador para a efetivação do contrato de trabalho para São Tomé e Príncipe correspondia a uma autocondenação. O contrato para o Sul era o último recurso a lançar mão, uma vez reconhecida a impossibilidade de emigrar para qualquer outro país".

6 A partir das leituras bergsonianas sobre o tempo e a memória (imagem lembrança e imagem atual), a noção de "cristal de tempo" em Deleuze (20I I: I03) articula-se com a noção de "imagem-cristal", que constitui a "operação mais fundamental do tempo: já que o passado não se constitui depois do presente que ele foi mas ao mesmo tempo, é preciso que o tempo se desdobre a cada instante em presente e passado". Por conseguinte, "o cristal, com efeito, não para de trocar as duas imagens distintas que o constituem, a imagem atual do presente que passa e a imagem virtual do passado que se conserva." E esses estados cristalinos Deleuze (20II: I03) nomeia "cristal de tempo": "o passado coexiste com o presente que ele foi; o passado se conserva em si, como passado geral (não cronológico); o tempo se desdobra a cada instante em presente e passado, presente que passa e passado que se conserva".

\section{REFERÊNCIAS BIBLIOGRÁFICAS}

Adichie, Chimamanda Ngozi. (2009). The danger of a single story. TedGlobal. Disponível em: <http://www.ted.com/ talks/chimamanda_adichie_the_danger_of_a_single_ story>. Acesso em io jun. 2012.

Andrade, Elisa. (I996). As ilhas de Cabo Verde - da "Descoberta" à Independência Nacional (I460-1975). Paris: Editions L'Harmattan.

Barbosa, Carlos Elias \& Ramos, Max Ruben. (2008). Vozes e movimentos de afirmação: os filhos de cabo-verdianos em Portugal. In: Góis, Pedro (org.). Comunidade(s) cabo- 
“SOMOS DESCENDENTES!” - CONTRANARRATIVAS E AGENCIAMENTOS MUSICAIS...

-verdiana(s): as múltiplas faces da imigração cabo-verdiana. Lisboa: Acidi, p. I75-194.

Carreira, António. (1984). Cabo Verde: aspectos sociais, secas e fomes do século XX. Lisboa: Ulmeiro.

Carreira, António. (1983). Migrações nas Ilhas de Cabo Verde. 2 ed. Lisboa: CEE/ICL.

Carreira, António. (1977). Classes sociais, estruturas familiares e migração em Cabo Verde. Lisboa: Ulmeiro.

Cidra, Rui. (2008). Produzindo a música de Cabo Verde na diáspora: redes transnacionais, world music e múltiplas formações crioulas. In: Góis, Pedro (org.). Comunidade(s) cabo-verdiana(s): as múltiplas faces da imigração cabo-verdiana. Lisboa: Acidi, p. I05-I26.

Deleuze, Gilles. (20II). A imagem tempo: cinema 2. São Paulo: Editora Brasiliense.

Deleuze, Gilles \& Guattari, Félix. (2008). Mil platôs: capitalismo e esquizofrenia, v.4. São Paulo: Editora 34.

Dos Anjos, José Carlos. (2006). Intelectuais, literatura e poder em Cabo Verde: lutas de definição da identidade nacional. Porto Alegre: UFRGS editora.

Fernandes, Gabriel. (2002). A diluição da África: uma interpretação da saga identitária cabo-verdiana no panorama político (pós)colonial. Florianópolis: Edufsc.

Furtado, Claúdio. (I997). Génese e reprodução da classe dirigente em Cabo Verde. Praia: ILCD.

Gilroy, Paul. (200I). O Atlântico negro: modernidade e dupla consciência. São Paulo: Editora 34.

Góis, Pedro \& Marques, José Carlos. (2008). Práticas transnacionais dos imigrantes cabo-verdianos em Portugal. In: Góis, Pedro (org.). Comunidade(s) cabo-verdiana(s): as múltiplas faces da imigração cabo-verdiana. Lisboa: Acidi, p. 87-Io4. Gonçalves, Carlos Filipe. (2006). Kab Verd Band. Praia: Instituto do Arquivo Histórico Nacional.

Nascimento, Augusto. (2008). Vidas de S.Tomé segundo vozes de Soncente. Lousã: Ilhéu Editora e do Autor.

Nascimento, Augusto. (2007). O fim do caminhu longi. Mindelo: Ilhéu Editora e do Autor.

Nogueira, Gláucia. (2015). Batuku de Cabo Verde: percurso histórico-musical. Praia: Edições Pedro Cardoso. 
Ribeiro, Jorge. (20I2) Inquietação, memória e afirmação no batuque: música e dança cabo-verdiana em Portugal. Tese de Doutoramento em Música. Departamento de Comunicação e Arte/Universidade de Aveiro.

São Tomé. (1903). Decreto-lei de I903. Boletim Official, 9. Semedo, Carla Indira. (2016). Ilusões do contrato? Migrações sul-sul, evocações do tráfico, contranarrativas e socialidades dos cabo-verdianos nas roças de São Tomé e Príncipe. Tese de Doutorado. PPGAS/Universidade Federal do Rio de Janeiro/Museu Nacional.

Semedo, Carla Indira. (2009). "Mara sulada e dã ku torno": performance, gênero e corporeidades no grupo de Batukadeiras de São Martinho Grande (Ilha de Santiago). Dissertação de Mestrado. PPGAS/Universidade Federal do Rio Grande do Sul.

Silva, Tomé Varela da. (I988). Ña Bibiñha Kabral. Bida y Obra. Praia: Instituto Cabo-verdiano do Livro.

Silva, Tomé Varela da. (I985). Finasons di Ña Nasia Gomi. Praia: Instituto Cabo-verdiano do Livro. 


\section{"SOMOS DESCENDENTES!" CONTRANARRATIVAS E AGENCIAMENTOS MUSICAIS DOS COLETIVOS DE TCHABETA NA ROÇA AGOSTINHO NETO (SÃO TOMÉ E PRÍNCIPE)}

Resumo

Cabo Verde, localizado na costa ocidental da África, é reconhecido como país marcadamente migratório. Entre vários destinos das pessoas cabo-verdianas, a experiência migratória em São Tomé e Príncipe foi concebida e narrada como o retrato da "pior migração" cabo-verdiana, por reverberar a experimentação da escravidão e reforçar uma negritude renegada. À luz da forma como a prática musicocoreográfica tchabeta aparece mobilizada no quotidiano das pessoas cabo-verdianas e os descendentes em São Tomé e Príncipe, as musicalidades constituem um mecanismo de reterritorialização e criação de um território existencial no arquipélago santomense. O que está em jogo é uma reatualização dos vários cristais de tempo: um batuko reprimido e silenciado do tempo colonial/do branco para um tchabeta que permite outros espaços e outros modos existenciais no território santomense.

\section{"WE ARE DESCENDANTS!" CONTRANARRATIVES AND MUSICAL AGENCIES OF THE COLLECTIVES OF TCHABETA IN ROÇA AGOSTINHO NETO (SÃO TOMÉ AND PRÍNCIPE)} trait of the Cape Verdean "worst migration", reverberating the experimentation of slavery and reinforcing a denied negritude. In light of the way the Tchabeta musical-choreographic practice appears mobilized in the practices of Cape Verdean people and the descendants in São Tomé and Príncipe, musicality is a mechanism of reterritorialization and creation of an existential territory in the São Toméan archipelago. And what is at stake is a re-updating of the various crystals of time: a repressed and silenced Batuko from colonial time/from white to a tchabeta which allows other spaces and other existential modes in the territory of São Tomé.
Palavras-chave

Tchabeta; reterritorialização; territórios existenciais; São Tomé e Príncipe; Cabo Verde.

\section{Keywords}

Gentrification; new-build gentrification; urban mobility; urban policies; socio-spatial inequalities. 